\title{
Políticas e práticas de educação inclusiva e a constituição social dos sujeitos com Distrofia Muscular de Duchenne
}

\author{
Géssica Torres Rozante* \\ Maria de Fátima Carvalho**
}

\begin{abstract}
Resumo
Este trabalho discute o papel desempenhado por políticas e práticas de educação inclusiva na constituição social de sujeitos com Distrofia Muscular de Duchenne e dificuldades decorrentes de sua progressão. Tem como aporte a psicologia histórico-cultural com destaque às contribuições de Vigotski sobre o caráter social do desenvolvimento humano. Os excertos discutidos são produtos de entrevistas abertas com um jovem com Distrofia Muscular de Duchenne (DMD) e sua mãe. A análise enfoca aspectos do processo de constituição social dos sujeitos, apontando para possibilidades de desenvolvimento psicológico na interação com contradições implicadas em discursos e práticas políticos-pedagógicos que perfazem sua educação escolar e sua história.

Palavras-chave: Psicologia histórico-cultural; Educação inclusiva; Constituição social dos sujeitos; Distrofia muscular de Duchenne

\section{Inclusive education policies and practices and the social constitution of Duchenne's Muscular Dystrophy} subjects
\end{abstract}

\begin{abstract}
This paper discusses the role that public policies and practices on inclusive education play on the social construct of subjects afflicted with Duchenne's Muscular Dystrophy and the difficulties associated with the disease's progression. Supported on historical-cultural psychology and specially Vigotski's contributions on human development's social character. The excerpts discussed are product of open interviews with a young man diagnosed with Duchenne's Muscular Dystrophy (DMD) and his mother. The analysis focuses on aspects of the social constitution process of the subjects, pointing to psychological development possibilities on the interaction with contradictions implicated in political-pedagogical discourses and practices that make their school path and their own history.

Keywords: Historical-cultural psychology; Inclusive education; Social constitution of subjects; Duchenne's muscular Dystrophy
\end{abstract}

\section{Introdução}

No contexto do estabelecimento de novas perspectivas, parâmetros e diretrizes para Educação Especial, objetivamos discutir, ao longo deste artigo, a faceta da Educação Inclusiva. Pretendemos analisar o papel desempenhado pelas políticas públicas e práticas escolares na constituição dos sujeitos com Distrofia Muscular de Duchenne (DMD). A especificidade do recorte analítico justifica-se pela complexidade da DMD, doença degenerativa que leva progressivamente à condição de deficiência motora e, portanto, altera significativamente as relações que os sujeitos estabelecem ao longo de seus percursos escolares com o meio, com os outros e com eles próprios. A literatura também aponta a incidência de deficiência intelectual em 30\% da população com DMD (NARDES; ARAÚJO; RIBEIRO, 2012). Tal panorama mobiliza-nos a estudar os percursos escolares de pessoas com DMD e ressaltar os modos como se constituem a partir das condições de possibilidades concretas, das experiências na/com a escola e dos enfrentamentos que vivenciam.

A DMD é uma doença que atinge 1 em cada 3.500 nascidos vivos e para qual ainda não há cura documentada na literatura médica. Caracteriza-se pelo comprometimento grave e irreversível da musculatura esquelética causada por um defeito bioquímico na célula muscular em decorrência de delação genética hereditária (FACHARDO; CARVALHO; VITORINO, 2004). O mau funcionamento da proteína chamada distrofina acomete progressivamente músculos esqueléticos, coração e cérebro, geralmente levando ao óbito na segunda década de vida em função de eventos cardiorrespiratórios. Clinicamente, observa-se sua manifestação na infância por conta do atraso na

\footnotetext{
*Endereço eletrônico: ge.rozante@gmail.com

**Endereço eletrônico: carvalhomdf@gmail.com
} 
motricidade dos membros inferiores ocasionando dificuldade de locomoção. A paresia evolui até a perda da marcha, geralmente por volta dos 12 anos e, progressivamente, afeta a região de cintura, membros superiores, pescoço e músculos respiratórios (SANTOS et al., 2002, p. 32).

A complexidade da DMD, sobretudo seu impacto sobre a vida dos sujeitos e de suas famílias, contrasta-se com a ausência de pesquisas que evidenciem a trajetória escolar desse público. O campo da Educação carece de reflexões acerca da peculiaridade de seus processos de escolarização, dos desafios que se apresentam nas práticas inclusivas e das alternativas encontradas concretamente nas escolas.

A discussão apresentada neste artigo tem como base o material produzido em pesquisa de mestrado, a qual foi concluída em 2016. Ao cotejarmos os percursos escolares de três sujeitos com DMD com os discursos e as práticas de inclusão escolar; evidenciamos as condições sociais que perfazem suas trajetórias escolares, bem como o papel dessas trajetórias como constitutivas de suas possibilidades de ser no mundo. Com isso queremos dizer que o modo como se realiza a educação escolar - com destaque para aspectos inclusivos/exclusivos - perfaz uma tensão social constitutiva da subjetividade desses jovens. Deste material, selecionamos uma das narrativas, que será analisada em profundidade e utilizada como referencial para a discussão que se seguirá.

Deste modo, diante das políticas e práticas de Educação Inclusiva, a constituição de sujeitos com DMD emerge como objeto de reflexão fundamentado pela complexidade de suas condições clínicas, pelas dificuldades decorrentes da progressão da doença, mas também, e centralmente, pela escassez de produção acadêmica sobre esse público no campo da Educação, apesar de marcado por um cenário de grande evasão escolar.

A discussão sobre a constituição social dos sujeitos tem como base os fundamentos da Psicologia Histórico-Cultural - e, nesse campo, especialmente as contribuições do teórico russo Lev S. Vigotski (2000; 2012a; 2012b)e seus interlocutores - e, nesse contexto, toma como eixo orientador as reflexões elaboradas por pesquisadores que desta perspectiva teórica abordam o caráter social dos processos de subjetivação, ressaltando o papel do outro-social. As contribuições de Mikhail Bakhtin (1998; BAKHTIN/VOLOCHINOV, 2014) foram também mobilizadas nesta análise, buscando observar o caráter dialógico desses processos.

\section{A constituição social dos sujeitos na perspectiva histórico-cultural}

"Através dos outros constituímo-nos" (VIGOTSKI, 2000, p 24). A enunciação de Vigotski em manuscrito de meados do século XX serve-nos como epígrafe a fim de anunciarmos os pressupostos teóricos sobre os quais este artigo se sustenta. Isto é, o que nos constitui como sujeitos singulares? Nossas formas de pensar, as vontades que nos impulsionam ou repelem as ações? Durante muito tempo a psicologia explicou os fenômenos da subjetividade recorrendo à ordem do intrínseco, seja a partir de explicações metafísicas, seja a partir do enfoque biológico que concebe o desenvolvimento como maturação das estruturas orgânicas. Buscava-se o pensamento, a memória e outras funções superiores no cérebro ou na abstração de uma ideia absoluta.

Ao enunciar que a constituição das subjetividades não é intrínseca ao sujeito, mas que, ao contrário, está no outro - ou melhor, nos outros é a dimensão social do desenvolvimento que Vigotski pretende apreender. Para o autor, diferente das funções elementares que se desenvolveram através do processo evolutivo, as funções superiores - isto é, tudo aquilo que nos distingue de outras espécies animais - só podem ser explicadas a partir de sua origem cultural e, sobretudo, histórica. Vigotski afirma ser impossível levar a cabo um estudo que se proponha a compreender as funções superiores sem que se dedique a uma abordagem, em algum nível, sociológica. Pois, para o autor, "por trás de todas as funções superiores e suas relações estão relações geneticamente sociais, relações reais das pessoas (VIGOTSKI, 2000, p.26).

Como destaca Pino (2005), o grande salto de Vigotski em relação às teorias que o precederam é a inversão do vetor que explica a constituição dos sujeitos. Para Vigotski importava compreender como o meio social age na criança criando funções psicológicas ou como o aparato biológico - com a emergência do cultural nas formas de sociabilização humanas - é redimensionado e ganha uma nova forma de existência no âmbito da cultura. Na interlocução com as ideias de Vigotski retomamos, entre outras, as contribuições de Smolka (1997, 2000); Góes $(2000,2004)$ e Pino $(1993,2005)$ sobre a formação do indivíduo nas relações sociais. Nessa direção:

Para nós, o importante é pensar o movimento dinâmico de constituição que envolve e faz emergir sujeito/discurso/conhecimento/sentido, o que implica considerar a dimensão histórico- 
cultural - que tem lugar somente no terreno interindividual - e indagar sobre suas condições de produção (SMOLKA, 1997, p. 39).

O caráter discursivo das relações interindividuais - lócus do movimento dinâmico de constituição dos sujeitos - e o papel central conferido por Vigotski à palavra e a interação verbal, nos permitem compreender, como explica Góes (2000), que a "construção social do indivíduo é uma história de relações com outros, através da linguagem". A construção dessa história possibilita “(...) transformações do funcionamento psicológico constituídas pelas interações face a face e por relações sociais mais amplas (que configuram lugares sociais, formas de inserção em esferas da cultura, papéis a serem assumidos etc.) (GÓES, 2000, p.121).

Dessa perspectiva, embora seja importante compreender a DMD em toda a sua complexidade orgânica e as transformações corporais que ela causa por sua progressão, a doença e a deficiência dela decorrente não são, por si, capazes de explicar como os sujeitos acometidos se constituem psicológica e socialmente. É nas formas de participação social que encontramos as tensões definidoras de seus percursos. Importa-nos destacar tais tensões porque estas são, sob esse fundamento, constitutivas de formas de ser no mundo. Elas constituem personalidades: pensamentos, vontades, afetos e sonhos.

Assim compreendemos que o sujeito é constituído no campo da intersubjetividade entendida como “(...) lugar de encontro, do confronto e da negociação dos mundos de significação privados (ou seja, de cada interlocutor) à procura de um espaço comum de entendimento e produção de sentido, mundo público de significação" (PINO, 1993, p. 22).

Encontramos em Bakhtin importantes contribuições para a discussão da constituição do sujeito, uma vez que ao enunciar que a "consciência só se torna consciência quando se impregna de conteúdo ideológico (semiótico) e, consequentemente, somente no processo de interação social" (BAKHTIN/VOLOCHINOV, 2014, p. 35), o autor desloca o olhar do indivíduo e anuncia o terreno das relações sociais, marcadas por fatores ideológicos e econômicos, como objeto de estudo.

Tal perspectiva é especialmente válida quando falamos de sujeitos cujos corpos se degeneram por conta da doença impondo novas formas de se relacionar, transformando constantemente a si e ao meio - tanto em seu âmbito espacial como no âmbito das relações sociais. Olhar a constituição do sujeito para além das explicações organicistas é dar fluidez para as condições de possibilidades e, por outro lado, evidenciar a construção da subjetividade nas relações com as políticas e práticas da inclusão escolar, ou seja, consiste em evidenciar os aspectos tensos, conflitivos e dramáticos dessa constituição.

\section{Metodologia}

Com objetivo de discutir aspectos da constituição social dos sujeitos no cerne de políticas e práticas de Educação Inclusiva apresentamos para análise a narrativa de um sujeito com DMD e de sua mãe acerca de suas trajetórias de vida, com especial foco sobre a narrativa acerca de sua experiência escolar. Os enunciados que serão apresentados são oriundos de entrevistas abertas e nos permitem discutir as múltiplas visões de mundo que se entrelaçam e, numa perspectiva histórico-cultural, entretecer e explicitar relações entre o singular e a totalidade, e o individual e o social, considerando também que, ao refletir e refratar a realidade na qual os sujeitos estão inseridos, os discursos também nos oferecem indícios de condições e modos de constituição dos sujeitos nessas relações.

Ao utilizarmos entrevistas abertas como método, trabalhamos com as contribuições de Rocha, Daher e Sant'Anna (2004) para quem a entrevista é capaz de capturar textos previamente existentes, mas que não foram ainda explicitados: "se recorremos à entrevista, é porque não temos acesso imediato a uma determinada 'massa de textos' que, de alguma forma, já deve existir (e cujo acesso não é imediato)" (ROCHA; DAHER; SANT'ANNA, 2004, p. 12). A entrevista é por nós compreendida como um dispositivo enunciativo e interativo de construção de discursos por parte dos sujeitos envolvidos - nesse caso, pesquisadora e sujeitos participantes do estudo. Essa massa de texto são as próprias experiências escolares dos sujeitos vividas por eles concretamente e (re)elaboradas na medida em que refletem sobre elas. Transformamos essa experiência em relato e, através da gravação e transcrição, criamos um produto textual novo e irrepetível, que é fruto do momento da enunciação (ROCHA; DAHER; SANT'ANNA, 2004).

Como afirma Axt (2008), nas pesquisas em Ciências Humanas o sujeito não pode ser estudado como coisa sobre a qual nos pronunciamos. A partir de uma perspectiva bakhtiniana afirma que o sujeito 
(...) não pode ser estudado, percebido a título de coisa, porque como sujeito de linguagem, não pode, em permanecendo sujeito, ficar mudo; e consequentemente o conhecimento que se tem dele só pode ser dialógico. Nesta via, dar voz ao sujeito da linguagem(...)significa trabalhar com as linguagens, com as possibilidades de expressão de sentidos nos encontros contextualizados, historicizados, em que os sentidos se produzem enquanto efeitos de um contexto vivencial, regido por uma ética das relações e uma estética da existência. É desses sentidos que propomos fazer a escuta: uma escuta instituída numa relação de solidariedade com a intervenção(...). (AXT, 2008, p. 96).

Tendo em vista a importância do conceito de dialogismo, da historicização e contextualização das situações nas quais emergem o discurso, apresentaremos os sujeitos de nosso artigo.

Carlos e Maria vivem em um bairro periférico da Grande São Paulo. Por entre as casas que aparentam estar sempre em obras, ruas, calçadas estreitas e ladeiras situa-se a casa onde moram também na companhia do pai de Carlos. Na região não há muitas opções de comércio e serviços públicos. Maria é técnica de enfermagem e atua em uma Unidade Básica de Saúde da cidade. O marido é marceneiro e pastor da igreja que a família frequenta.

Em função da DMD, Carlos não tem mobilidade da cintura para baixo, mas é capaz de movimentar os braços e manipular objetos. Também movimenta o pescoço e possui uma boa articulação mandibular. Movimenta o tronco com dificuldade. A família conta com alguns recursos e adaptações que permitem que Carlos circule pela casa e por outros espaços de socialização (seja educacional, de lazer ou religioso): uma espécie de guindaste no teto do quarto que facilita a transição da cama para a cadeira, uma cadeira motorizada e um carro adaptado. Esses recursos, mais do que explicitar a condição econômica da família, desvelam a rede de apoio que se constitui ao redor desta família, formada principalmente pela comunidade religiosa que se mobiliza para auxiliá-los.

$\mathrm{Na}$ época da entrevista, Carlos fazia um curso técnico administrativo através de um projeto de inclusão no ensino profissionalizante e no mercado de trabalho de uma instituição privada sem fins lucrativos. Fez toda sua Educação Básica no ensino público regular e sem reprovação. Demonstra grande interesse em seguir os estudos e fazer graduação na área de Ciências da Computação, além de conseguir um trabalho e encontrar uma namorada.

\section{O aluno com DMD no contexto político- pedagógico de inclusão: a constituição social dos sujeitos em discussão}

Para que possamos evidenciar a inserção da pessoa com deficiência na escola regular como tensão social constitutiva é preciso explicitar a dimensão histórica e cultural dessa tensão e, assim, não podemos desconsiderar a transformação histórica referente à concepção do lugar social que essas pessoas podem ocupar. Ainda no início do século XX, a escola regular não era um desses lugares. Vigorava a classificação que dividia alunos entre "normais" e "anormais" de acordo com as necessidades educativas específicas e, mesmo quando as deficiências não eram consideradas severas, as pessoas eram inseridas nas classes ou escolas especiais, sendo mantidas fora da escola regular (KASSAR, 2004).

A grande transformação foi a mudança do paradigma do assistencialismo para a perspectiva dos direitos humanos (SOUZA, 2013). Isto é, questões relativas à pessoa com deficiência deixaram de ser do âmbito da tutela familiar ou das instituições e passaram a fazer parte dos princípios do direito e responsabilidade do Estado, tendo como aporte a formulação dos direitos dos homens e cidadãos no âmbito internacional e, o processo de redemocratização brasileiro, nos anos 80 , que fomentou uma série de debates no bojo da formulação de uma nova carta magna. A partir deste processo, o acesso à Educação Básica pela pessoa com deficiência passa a ser previsto pela Constituição vigente como direito fundamental dos(as) brasileiros(as) e, destaca-se, como um dever compartilhado entre Estado - através da garantia de igualdade de condições de acesso e permanência no ambiente escolar - e família (BRASIL, 1988). Além disso, o país é signatário de uma série de documentos internacionais que versam sobre o direito à educação no âmbito dos direitos humanos e que, uma vez ratificados pelo Governo Federal, consolidaram-se como emendas constitucionais e passaram a preconizar, no âmbito legislativo, a educação básica gratuita e como direito universal como direito legalmente em todo território nacional.

No âmbito da educação da pessoa com deficiência, a Declaração de Salamanca, de 1994, é referida como um marco importante e exerceu grande influência na lei que disporia sobre as diretrizes e bases da educação. Segundo a Lei n. 9.394, de 20 de novembro de 1996, mais conhecida como Lei de Diretrizes e Bases da Educação Nacional (LDB), no 
art. 58; "Entende-se por educação especial, para os efeitos desta Lei, a modalidade de educação escolar oferecida preferencialmente na rede regular de ensino, para educandos com deficiência, transtornos globais do desenvolvimento e altas habilidades ou superdotação" (BRASIL, 1996).

Portanto, entendemos que do ponto de vista legislativo, no âmbito federal, a partir da LDB de 1996, a educação da pessoa com deficiência é preferencialmente de modalidade escolar, isto é, assume a prerrogativa inclusiva e faz parte da educação geral, ainda que não abra mão do atendimento especializado em casos em que seja mais adequado ao aluno, como mostra o Art. 58:

$\S 1^{\circ}$ Haverá, quando necessário, serviços de apoio especializado, na escola regular, para atender às peculiaridades da clientela de educação especial. $\S 2^{\circ} \mathrm{O}$ atendimento educacional será feito em classes, escolas ou serviços especializados, sempre que, em função das condições específicas dos alunos, não for possível a sua integração nas classes comuns de ensino regular (BRASIL, 1996).

Mesmo que represente avanços quanto ao direito à educação da pessoa com deficiência no âmbito, preferencialmente, da escola regular através da organização de uma rede de serviços de apoio especializado, o posicionamento da LDB não se traduziu em práticas transformadoras. A forma ambígua como as diretrizes abordaram a organização da Educação Especial e da escola comum no contexto inclusivo, deixava margem à dúvida $\mathrm{e}$ mantinha-se a possibilidade de entendimento e realização do atendimento educacional especializado como substitutivo à escolarização (BRASIL, 2015).

Em 2001, confrontando as contradições acima apontadas, as Diretrizes Nacionais para a Educação Especial na Educação Básica, contidas na Resolução CNE/CEB n ${ }^{\circ}$ 2/2001, no artigo $2^{\circ}$, determinam que "os sistemas de ensino devem matricular todos os alunos, cabendo às escolas organizarem-se para o atendimento aos educandos com necessidades educacionais especiais, assegurando as condições necessárias para uma educação de qualidade para todos. (BRASIL, 2001)

Nesse contexto de princípios e proposições, em 2009 o Brasil torna-se signatário da Convenção sobre os Direitos das Pessoas com Deficiência (BRASIL, 2009), aprovada pela ONU em 2006 que estabelece que "[...] os Estados-Partes devem assegurar um sistema de educação inclusiva em todos os níveis de ensino, em ambientes que maximizem o desenvolvimento acadêmico e social compatível com a meta da plena participação e inclusão" (BRASIL, 2015, p. 10).

A atual Política Nacional de Educação Especial na perspectiva da Educação Inclusiva (BRASIL, 2008) tem como principal objetivo assegurar a inclusão escolar de alunos com deficiência, transtornos globais do desenvolvimento e altas habilidades/superdotação nas turmas comuns do ensino regular.

No âmbito de todas essas orientações e prescrições legais, o percurso escolar de Carlos vai ganhando forma, assim como suas possibilidades de ação como estudante, como cidadão, como pessoa de direito. Com as lembranças de Carlos e Maria, não pretendemos fazer uma recomposição histórica do processo de inclusão educacional, mas evidenciar como tal processo foi vivenciado pelos sujeitos que dele participaram. Como nos lembra Ecléa Bosi, a memória parte sempre do presente, que influencia no que ou em como algo será lembrado (BOSI, 2003). A partir dessas visões de mundo podemos tecer as relações das experiências que são individuais, mas também sociais, pois são fruto de transformações de contexto histórico, político, econômico e social.

Buscamos evidenciar na análise, a partir da trajetória de vida de Carlos e, indiretamente, de Maria, como as políticas e as práticas de educação inclusiva se efetivam e como os afetam: como as relações estabelecidas vão constituindo-os como sujeitos.

Em 1997, ano do nascimento de Carlos, ecos da LDB já ressoam no campo da educação de pessoas com deficiência trazendo à tona as contradições constitutivas do processo de inclusão escolar desses alunos e impactando o início de sua trajetória. Apesar dos sintomas terem se manifestado desde os três anos, a família só conseguiu um diagnóstico quando Carlos tinha seis anos e meio.

Maria: A biópsia do músculo, né? Foi feita na perna. Porque é uma coisa muito perigosa. Aí fizemos lá em São Paulo e, infelizmente, deu distrofia, né?

Carlos: Ai com 9 anos e meio parei de andar.

Pesquisadora: Com 9 anos e meio?

Maria: Aí fomos à luta, ai a gente... Ele andava até 9 anos e meio.

Carlos: Aí eu faltei uma época na escola.

Pesquisadora: Ele já tava na escola até você ter o diagnóstico?

Maria: Já, estava normal.

Pesquisadora: $E$ aí vocês mantiveram ele 
na escola?

Maria: Mantivemos. Nós comunicamos o diretor e era muito bem cuidado, né?

Pesquisadora: Teve alguma dificuldade na escola nessa época?

Carlos: Não, a escola era muito boa, na EMEB.

Carlos já estava matriculado na escola regular e, apesar do impacto do diagnóstico, a família decidiu mantê-lo em sua rotina escolar, ainda que com algumas faltas. Embora já apresentasse dificuldades de locomoção, como o fato de que precisava andar apoiado na parede para não cair, a família não encontrou grandes barreiras no início do processo de escolarização.

Maria: Depois que ele saiu da Municipal, ele teve essa dificuldade, porque na municipal ainda ele andava e tinha apoio melhor. E ai quando foi pra essa escola do primeiro grau, já tive essa dificuldade, porque eram os alunos, um aluno que ajudava ele. E por ser adolescente ai teve alguns comentários, entendeu? Desagradável. Tipo assim, professora e inspetor não estavam nem aí pro Carlos, só tinha ele de especial na escola, cadeirante, eu digo. E achei que o suporte não foi adequado, por isso eu tirei ele dali, da escola aqui.

Pesquisadora: Ele ficava exposto, assim, aos amigos, né?

Maria: Ai começaram a comentar, que era só um menino que levava, que era até um amigo dele...

Pesquisadora: Ah, entendi agora. Eles faziam comentários, fazendo sugestões que vocês...

Carlos: É, zoava. Acho que zoava também eu acho que não lembro.

Pesquisadora: Ah, entendi.

Carlos: Ai eu sai de lá, né?

Conforme a condição orgânica vai se tornando mais complexa em função da progressão da doença, a inserção da pessoa com DMD também exige maiores transformações no meio escolar e evidencia contradições das práticas inclusiva. Em uma discussão bastante profícua sobre o direito universal do homem, ou o que hoje podemos compreender como Direitos Humanos, Bobbio (2004) explicita como as definições desses direitos são expressões vagas e, quase sempre, redundantes, ou seja, trata-se de expressões genéricas que são empregadas na escrita de documentos como estratégia de concertação entre atores que antagonizam no momento da redação, mas que não resolvem as contradições ideológicas e políticoeconômicas subjacentes a estes mesmos direitos (BOBBIO, 2004). Disto implica que, no momento que se passa da enunciação verbal para a aplicação, tais contradições emergem com muita força.

É a contradição que fica evidente no episódio rememorado por Maria e silenciado por Carlos: ao não contar com apoio de um auxiliar de vida escolar, Carlos fica exposto aos amigos, tanto física quanto psicologicamente. Apesar da imprecisão da referência ao ano, seu relato recupera a transição para o $6^{\circ}$ ano do ensino fundamental - entre os anos de 2007 e 2008 - portanto o acontecimento relatado se realiza no bojo das discussões e publicações de decretos com garantias legais do acesso e permanência para pessoas com deficiência na escola regular. É possível discutir o impacto da experiência em Carlos a partir de seu silenciamento: na maior parte da entrevista Carlos foi a voz da própria narrativa - como em episódios nos quais a pesquisadora realiza perguntas voltada para a mãe, tratando Carlos na terceira pessoa, "ai vocês mantiveram ele na escola?(...) Teve alguma dificuldade na escola nessa época?" Sem tardar ele reivindica seu turno de fala afirmando que "não, a escola era muito boa"; entretanto, no momento em que sua mãe enuncia um episódio no qual fica exposto às insinuações dos colegas, ele se torna menos comunicativo. Chega a afirmar que aconteciam comentários por parte dos outros amigos, mas não se detém nessa lembrança. Sua fala "ah, zoava, né? Acho que zoava também... eu acho que não lembro".

$\mathrm{O}$ que significa seu esquecimento nesse contexto? Assim como a memória é mediada pelo signo, pelo outro, pelas interações sociais, também o é o esquecimento: "Quem esquece não é um organismo, um cérebro. Quem esquece é uma pessoa" (BRAGA, 2004, p. 596) que vive os dramas e as angústias de ser quem é e de ter vivido o que viveu. Esquecer, nesse caso, é também silenciar o doloroso, o constrangedor. É imbuir-se do direito de não dizer aquilo que não gostaria que fosse dito. Diante da experiência negativa, a família busca caminhos; busca outras escolas possíveis até que faz a transferência de Carlos. Emerge a importância de ter escolha, de optar pelo melhor lugar para realizar seu processo educativo. O alívio que se reflete no modo como pontua o final do episódio "aí eu saí de lá, né?". 
Em meio aos relatos, fica evidente que a escola regular é o lugar de Carlos, por direito e por desejo. Em nenhum momento a mãe diz que pensou em interromper o processo de escolarização, com todas as barreiras que a escola ainda apresenta, tampouco sugeriu que Carlos não a frequentasse. Há mudança de escola, mas não há evasão.

Pesquisadora: $E$ você já teve problema, alguma dificuldade, em termos de conseguir a matrícula dele nessas escolas?

Maria: Não, nunca. Cheguei e... primeiro que essa dai é dificil conseguir vaga. Ai quando eu fui, a primeira vez eu quis que (inaudivel) nessa escola. Cheguei assim, até me assustei, que eu pensei que "ah, então tá, vamos esperar um pouco" e ela falou "traz o documento dele, tá?" e na mesma hora eu fiz a matrícula. Então foi assim, portas abertas mesmo. Ai começamos a ter essas dificuldades, né? Do elevador, porque eles colocavam ele no primeiro andar. Ai comecei também, toda hora reclamava com a diretora e eles ficavam lá, mó frio no pátio, na época do frio.

A facilidade de matricular seu filho surpreende Maria, que vivenciou uma época em que a educação de pessoas com deficiência estava restrita ao âmbito institucional especializado. Ela se surpreende e se alegra com a possibilidade: "portas abertas". Mas, logo constata e aponta que não basta encontrar portas abertas, em seu relato também se manifestam as dificuldades que constituem a experiência de inclusão escolar. Faz referência à dificuldade enfrentada para garantir que Carlos seja atendido em suas especificidades relacionadas à enfermidade, como por exemplo, os riscos de estar susceptível ao frio para as pessoas com $\mathrm{DMD}^{1}$, além de suas condições de mobilidade que exigem acessibilidade.

O episódio do elevador também é lembrado pelo próprio Carlos.

Carlos: Ah! Tenho que falar uma coisa da escola também! Que eu sofri muito foi quando do [Nome da escola], que mandavam eu estudar lá em cima. Ai tinha elevador, o elevador quebrava toda hora.

Pesquisadora: Nossa!

Carlos: Tinha uma vez, foi na $7^{a}$ série, que eu estudei num laboratório, um cheiro horrivel. Só por causa que não tinha sala, porque tava usando a outra sala de baixo.

Pesquisadora: $E$ você já chegou a ficar preso no elevador?

Carlos: Não! Graças a Deus não! Eu ia ficar com trauma.

Pesquisadora: Aí, quando o elevador quebrava, como você fazia? Eles colocavam sua sala no laboratório?

Carlos: É! Levavam no laboratório. Minha mãe até corria atrás pra resolver, né mãe? Os casos...

Pesquisadora: Demorava muito tempo pro elevador...

Carlos: Demorava.

Maria: Era uma luta.

Carlos: Era uma luta. Os pais brigavam. Foi na $7^{a}$ série.

Maria: Ai acaba sofrendo ele e alguns alunos. Às vezes, também toda a classe.

Sujeito/ideologia/subjetividade. Do Carlos que esquece, passamos pro Carlos que denuncia: "Ah! Tenho que falar uma coisa da escola também! Que eu sofri muito". Ao reivindicarem direitos, Carlos e Maria apontam para apropriação de um discurso de direitos que se faz ecoar a partir das políticas e contextos de inclusão. Denunciam a escola que por vezes tem estrutura, mas não tem manutenção e os desdobramentos inadequados da distância entre a política e sua implementação. Sua fala também diz dos impasses vividos pela escola: onde acomodar o grupo quando não é possível ir ao primeiro andar do prédio sem elevador? Como deslocar o aluno que faz uso de cadeira de rodas? A alternativa de manter o grupo com ele, que nos parece uma opção coerente frente aos objetivos de inclusão, por sua vez, como diz a mãe, podia gerar sofrimento em todo o grupo: "Ai acaba sofrendo ele $e$ alguns alunos. Às vezes, também toda a classe", que como diz Carlos, junto com ele era submetida aos desconfortos de fazer aula em espaços improvisados, como "num laboratório, (com) um cheiro horrivel (...). Só por causa que não tinha sala, porque tava usando a outra sala de baixo".

Carlos se apresenta como um sujeito crítico que, ao rememorar suas experiências escolares, tem condições de visualizar e expressar aquilo que the pareceu injusto. Não naturaliza, pois, as condições de permanência que lhe foram oferecidas, tampouco contenta-se com os ajustes feitos. Nessa direção, as análises de Smolka (1997) sobre processos discursivos, ideologia e subjetividade ampliam nossa compreensão. Para a autora,

essa resistência explícita delineia o caráter dramático da enunciação: o próprio movimento de circunscrição e resistência do sujeito, na/pela linguagem, insere-se no conjunto de regras 
anônimas (FOUCAULT, 1986), deixando ecoar uma voz generalizada, normativa, estabilizada (SMOLKA, 1997, p. 42).

A palavra "luta" é muito comum na entrevista e o vocabulário aparece em outras passagens nos permitindo refletir sobre a multiplicidade de sentidos articulados ao discurso de inclusão escolar, de direito à educação e seus efeitos sobre os sujeitos. Para Bakhtin (1998, p. 100), "a palavra da língua é uma palavra semi-alheia. Ela só se torna própria quando o falante a povoa com sua intenção, com seu acento, quando a domina pelo discurso, torna-a familiar com sua orientação semântica e expressiva".

Carlos e Maria tornam próprio de suas falas o termo luta, luta por direito à escola/educação e, assim, reiteram o discurso de inclusão escolar, ao mesmo tempo em que o problematizam. Evidenciam a sobreposição da ideia de direito à educação escolar como sentido dominante, como o que orienta as posições assumidas pelos sujeitos nos contextos de embates. Isso aparece de forma mais emblemática, quando falávamos sobre o trâmite para conseguir uma profissional - auxiliar de vida escolar - já no ensino médio.

Pesquisadora: A cuidadora vocês conseguiram quando?

Carlos: Foi... Não sei quem conseguiu aí. Batalha das mães.

A luta pela escolarização evidencia-se como um dos aspectos constitutivos da vida social de Carlos e da experiência do ser criança e adolescente no atual momento histórico brasileiro. Em seu caso, embora haja o acesso à escola, é necessário lutar por condições de permanência. As mães emergem nesses processos de "luta" como condição constitutiva de possibilidades de percurso escolar de seus filhos: seus engajamentos e disposição são cruciais para a permanência deles na escola, pois a despeito da legislação existente - que garante, formalmente, a Carlos o acesso à escola - essa "inclusão" não se faz sem tensão: ainda é preciso "toda hora reclamar com a diretora", e eles reclamam e exigem porque sabem que têm direito. Agem responsivamente, dialogando com contexto histórico e político que enuncia a escola como local de aprendizagem da pessoa com deficiência. Em seus enunciados dialogam com as condições concretas da escola que muitas vezes aparecem como barreira.

Faz-se notar o conceito de dialogismo bakhtiniano, explicitado por Fiorin da seguinte maneira:
A apreensão do mundo é sempre situada historicamente, porque o sujeito está sempre em relação com outro(s). O sujeito vai constituindose discursivamente, aprendendo as vozes sociais que constituem a realidade em que está imerso, e, ao mesmo tempo, suas inter-reçaões dialógicas. Como a realidade é heterogênea, o sujeito não absorve apenas uma voz social, mas várias, que estão em relações diversas entre si. Portanto, o sujeito é constitutivamente dialógico. Seu mundo interior é constituído de diferentes vozes em relações de concordância ou discordância. Além disso, como está sempre em relação com o outro, o mundo exerior não está nunca acabado, fechado, mas em constante vir a ser. (FIORIN, 2006, p 55)

É importante ressaltar que o conceito de dialogismo em Bakhtin não está atrelado à ideia de um diálogo face a face entre os interlocutores, mas trata-se de um diálogo entre discursos. O papel do social - do outro constitutivo - se evidencia. De acordo com Góes (1994, p. 27) esse papel "revela-se contraditório". Conforme a autora, "o jogo dialógico entre sujeitos não tende a uma só direção: ao contrário, envolve circunscrição, ampliação, dispersão e estabilização de sentidos". Assim, podemos entender como das vivências escolares, ressoam boas lembranças que remontam à presença de outros jovens com deficiência na sala de aula. Como no episódio em que Carlos chega com uma cadeira motorizada na escola.

Carlos: Eu lembro na escola também, era bom demais, todo mundo achava estranho, "Nossa, Carlos de cadeira motorizada", eles ficaram surpresos, né mãe?

Pesquisadora: $E$ ? $E$ você chegou no meio do periodo, já tinha começado as aulas, e aí de repente você chegou com a cadeira motorizada?

Carlos: Meu amigo ficou com ciúmes, ele que era de muleta, ai falou "Você me largou agora". Ai, no começo, nós brigamos e depois voltou a falar de novo.

Pesquisadora: Ah, vocês chegaram a brigar por causa da cadeira?

Carlos: Ele brigou, ficou com ciúme. Porque eu largava ele e andava de cadeira de rodas.

Pesquisadora: $E$ então fez uma diferença muito grande, Carlos, isso? A cadeira motorizada pra você?

Carlos: Fez! Ninguém precisa empurrar mais eu. E eu vou pro lugar que eu quero ir. 
As contradições que entretecem a relação de Carlos (e de sua mãe) com a escola - com a educação escolar - com políticas e práticas de educação inclusiva nos permitem entender que, se queremos considerar a dinamicidade e a complexidade constitutiva dessa relação, não podemos desconsiderar especificidades que circunscrevem as interações vividas/lembradas na/da escola. A relação é de tensão, sofrimento, esquecimentos, mas também de poder, de se saber sujeito de direito, de exigir, de dispor de recursos. A luta é legitimada pela legislação, promovida por esta e, ambas - a lei e a luta (das mães) - reiteram a importância da existência de suportes, de disponibilização de recursos, estratégias e serviços de Tecnologia Assistiva (TA) concorrendo para a independência conquistada com a cadeira de rodas.

Sobre a rotina atual de Carlos, no curso profissionalizante eles nos dizem

Maria: Né? Porque tem cadeirante que tem força, ele pega ali e puxa, né? É diferente, agora eles não. Eles precisam de todo o apoio, né? Pra pegar... Até pra comer, até falei pra ele que se precisar, a pessoa que cuida dele ia lá na hora dele se alimentar e na hora que ele fosse pra sala, vinha embora. Mas ele quer se virar sozinho.

Carlos: Eu consigo. Falo assim "Põe pra mim aí" aí ele coloca lá e eu como.

Enquanto as dificuldades decorrentes da DMD se intensificam, as vivências promovem a vontade de independência e a tensão entres ambas revela na referência ao suporte oferecido por uma auxiliar de vida escolar, na escola, como uma necessidade

Carlos: Ah, era bem, né? Quando nós chegava no transporte já pegava nós, já pegava nossa mochila, ai recebia nós, levava pra sala, apanhava mochila, apanhava material, ai depois saía e deixava nós lá. Pra nós ficar também livre dela, né? Ficar o dia inteiro não dá.

Evidencia-se a vontade de liberdade, de autonomia e a necessidade de acesso aos recursos que a viabilizam e limitam. O acesso aos recursos, como a cadeira motorizada, bem como experiências de depender do outro e, ser exposto, constrangido como no episódio do banheiro, vai constituindo a personalidade de Carlos que se coloca muitas vezes como um sujeito autônomo e capaz. Ele precisa de suporte, mas solicita apenas para aquilo que julga ser realmente necessário.

Assim, para além da importância do aumento de acessibilidade e independência relacionadas à cadeira, a experiência escolar é referida como uma experiência boa, engrandecedora: "Eu lembro na escola também, era bom demais...", em uma fala que remete ao relato da cumplicidade vivida, que se expressa em: orgulho, ciúmes, amizade. A experiência de Carlos é marcada também pela presença de outras pessoas com deficiência.

Pesquisadora: $E$ você tinha um amigo que também tinha...que usava muleta, por quê?

Carlos: Ele tinha problema, não sei o nome. Tinha outros que também tinha problema, não era só eu não.

Pesquisadora: Na sua sala?

Carlos: Na minha sala tinha um de muleta e um outro, que eu comecei a estudar no colegial.

Maria: Essa escola que ele estudou o Ensino Médio tinha bastante especial.

Carlos: Lá tinha, no [nome da escola] tem muito.

Maria: Quando o Carlos foi, já tinha uns 7.

Carlos não era o único rapaz com deficiência na escola. Coloca-se a possibilidade de construção dos modos de significar a DMD e a si mesmo pautada nas aproximações e distanciamentos com as pessoas com e sem deficiência. Góes (2004) faz uma importante reflexão sobre como esse processo de inclusão escolar afeta a formação da pessoa com deficiência e afirma que se o processo de construção de identidade se faz através da relação com os semelhantes e os diferentes "os alunos especiais estão tendo poucas oportunidades (por vezes, nenhuma) de elaborar a semelhança em relação àqueles que tem o mesmo tipo de necessidade especial, assim reconhecida e classificada pelo grupo social" (GÓES, 2004, p. 81).

A experiência escolar é constitutiva da personalidade de Carlos, que através do outro - seja aproximando-se ou distanciando-se - vai definindo um modo de ser no mundo. "Mas ele quer se virar sozinho" é uma forma de concebê-lo que vem do outro.

Retomamos a perspectiva de Vigotski sobre o desenvolvimento cultural e os três estágios: em si, para outros e para si (VIGOTSKI, 2000). Carlos, em função de suas experiências de vida - abordadas aqui a partir de um recorte que considera apenas o âmbito escolar, mas está longe de ser a totalidade de suas vivências - apresenta-se como um sujeito 
independente que é reconhecido pelo outro, no caso, a mãe. Esse reconhecimento corrobora em uma autoafirmação que será sustentada inúmeras vezes por Carlos e que, inclusive o projeta: "eu consigo". Não há aqui uma ode à autonomia como valor maior, ao contrário, fica-nos claro que ele consegue também, porque há recursos que o possibilitam, seja em termos técnicos, seja pela afirmação do outro.

Os dizeres de Carlos nos aproximam da ideia de drama em Politzer e Vigotski. Em Politzer (1973) o ponto de vista psicológico é aquele que coincide com o drama.

Escolhendo o drama para campo de estudo, o acto constitutivo da ciência psicológica deixa de ser uma percepção qualquer (...). Com efeito, um gesto que eu faça é um ato psicológico, porque é um segmento do drama que representa minha vida. A maneira como ele se insere nesse drama é dada ao psicológo pela narrativa que eu possa fazer acerca do referido gesto. Mas o fato psicológico é o gesto esclarecido pela narrativa e não o gesto isolado ou conteúdo realizado da narrativa. (...) Ora, o facto psicológico não é o comportamento simples mas precisamente o comportamento humano, isto é, o comportamento reportado aos acontecimentos pelos quais se desenvolve a vida humana e ao indivíduo enquanto sujeito dessa vida. (POLITZER, 1973, p. 111-112)

Vigotski (2000, p.26), retomando Politzer, reflete: "psicologia $=$ drama (...), o drama realmente está repleto de ligações de tal tipo: o papel da paixão, da avareza, dos ciúmes, em uma dada estrutura da personalidade". Delari Junior, retomando a discussão do drama em Vigotski, enfatiza que esses conflitos são algo que "apenas o ser humano concreto pode viver, por conta dos diferentes impasses que ele vivencia somente como ser social" (DELARI JUNIOR, 2011, p. 185).

E assim o é no bojo das relações: luta, cumplicidade, briga, ciúme, perdas e conquistas. No movimento dinâmico de constituição dos sujeitos, marcado pela lembrança e esquecimento, adesão e ruptura, capacidade de escolha e dependência, se tensionam, dão forma ao drama - movimento dinâmico de constituição dos sujeitos na relação com outro, na relação com o mundo.

\section{Considerações Finais}

O que objetivamos nesse artigo foi, a partir das narrativas sobre o processo de escolarização de um jovem com DMD, enfocar aspectos do processo de constituição social dos sujeitos, apontando possibilidades de desenvolvimento psicológico na interação com contradições implicadas em discursos e práticas de educação inclusiva.

A partir de uma perspectiva históricocultural buscamos apontar como a vivência escolar incide sobre o sujeito e sua família (aqui sintetizada na figura da mãe), contingenciando modos de ser uma posição frente à vida. Trata-se ainda de dar visibilidade à experiência de inclusão escolar significada por aqueles que dela participam. Importanos, sobremaneira, destacar as tensões explicitando que se o discurso político não garante práticas inclusivas, este é fundamental para empoderar os sujeitos na luta pelos seus direitos. A grande conquista que identificamos, de quase duas décadas de políticas públicas é, especialmente, a ideia de que o lugar da pessoa com deficiência é no seio da escola regular. Tal perspectiva viabiliza a luta pelo acesso e permanência que acontece nas bases, cotidianamente, como "luta das mães". Entretanto, com a experiência de Carlos, também nos fica evidente que, quanto mais complexas são as especificidades do aluno frente às demandas escolares, mais se apresentam os limites da escola contemporânea nesse processo.

Por fim, buscamos desvelar a importância de políticas e práticas de educação inclusiva na experiência escolar vivida a partir de seu aspecto constitutivo da personalidade do sujeito com deficiência (e de sua mãe), neste caso a DMD. As tensões sociais que a conformam, refletem e refratam na forma como esses sujeitos compreendem o mundo, nele se posicionam e se concebem enquanto pessoa, nos seus projetos e desejos.

Pesquisadora: Os seus planos, quais são?

Carlos: Ah, fazer faculdade e estar efetivado na empresa, é isso.

Maria: Trabalhar pra ganhar bem, ajudar a mãe.

Carlos: Não tenho namorada também. Queria encontrar, mas não...Vou procurar [...]. No tempo certo vai chegar, né? Não pode ficar apavorado.

Pesquisadora: Mas você já tem suas paqueras? As meninas que você gosta?

Carlos: Tem!

Maria: $A i, a i, a i \ldots$

Carlos: Tem, né? Vida normal do ser humano, né? 


\section{Nota}

1 A fraqueza muscular respiratória é umas das características clínicas da DMD, de modo que doenças que causam algum tipo de insuficiência respiratória podem ser extremamente graves para esse público.

\section{Referências}

AXT, M. Do pressuposto dialógico na pesquisa: o lugar da multiplicidade na formação (docente) em rede. Informática na Educação: Teoria \& Prática. Porto Alegre, v.11, n.1, jan./jun.2008.

BAKHTIN, M. Questões de Literatura e de Estética: A Teoria do Romance. $4^{\mathrm{a}}$ Ed. São Paulo: Hucitec, 1998.

BAKHTIN, M. / VOLOCHINOV. Marxismo e

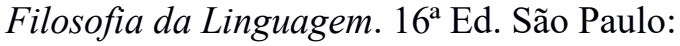
Hucitec, 2014.

BOBBIO, N. A era dos direitos. $1^{\text {a }}$ Ed. Rio de Janeiro: Campus, 2004.

BOSI, E. O tempo vivo da memória: ensaios de Psicologia Social. $3^{\text {a }}$ Ed. São Paulo: Ateliê Editorial, 2003.

BRAGA, E. S. Esquecer para lembrar e ser. In: MENEZES, M. C. (Org). Educação, memória, história: possibilidades, leituras. Campinas, SP: Mercado de Letras, 2004.

BRASIL. Constituição da República Federativa do Brasil. Brasília: Senado Federal, 1988.

. Lei n. 9.394, de 20 de dezembro de 1996.

Estabelece as Diretrizes e Bases da Educação Nacional. Brasília, DF. Recuperado em 20 de agosto de 2018, de

http://www.planalto.gov.br/ccivil_03/leis/L9394.htm.

. Ministério da Educação. Resolução ${ }^{\circ} 2$ de

11 de setembro de 2001. Institui Diretrizes

Nacionais para a Educação Especial na Educação

Básica. Brasília, DF. Recuperado em 20 de agosto de 2018 , de

http://portal.mec.gov.br/arquivos/pdf/resolucao2.pdf . Política Nacional de Educação Especial na perspectiva da educação inclusiva. De 07 de janeiro de 2008. Brasília, DF. Recuperado em 20 agosto de 2018, de

http://portal.mec.gov.br/arquivos/pdf/politicaeduces pecial.pdf

. Convenção sobre os direitos da pessoa com deficiência. Dec. 6.949/2009 (Decreto do Executivo) 08/25/2009. Recuperado em 20 de agosto de 2018, de http://www.planalto.gov.br/ccivil_03/_ato20072010/2009/decreto/d6949.htm

\section{. Orientações para implementação da}

Política de Educação Especial na perspectiva da Educação Inclusiva. 2015. Recuperado em 20 de agosto de 2018,

http://portal.mec.gov.br/index.php?option=com_doc man\&view $=$ download\&alias $=17237$-secadidocumento-subsidiario-2015\&Itemid $=30192$

DELARI JUNIOR, A. Sentidos do "drama" na perspectiva de Vigotski: um diálogo no limiar entre arte e psicologia. Psicologia em Estudo. Maringá, v. 16, n. 2, p. 181-197, abr/jun. 2011.

FACHARDO, G. A.; CARVALHO, S. C. P. D.; VITORINO, D. F. D. M. Tratamento hidroterápico na distrofia muscular de Duchenne. Revista Neurociência, São Paulo, v. 12, n. 4, p. 217-221, out/dez 2004.

FIORIN, J. L. Introdução ao pensamento de Bakhtin. 1ªd. São Paulo: Ática, 2006.

GÓES, M.C.R; SMOLKA, A.L.B. As relações intersubjetivas e construção do conhecimento. In: GÓES, M.C.R; SMOLKA, A.L.B. (Org). A siginificação nos espaços educacionais. $1^{\mathrm{a}} \mathrm{Ed}$. Campinas: Papirus, v. 1,p. 11-28.

GÓES, M. C. R. A formação do indivíduo nas relações sociais; contribuições teóricas de Lev S. Vigotski e Pierre Janet. Educação e Sociedade. Campinas, XXI, n.71, p.116-131, jul/ 2000.

Desafios da inclusão de alunos especiais: a escolarização do aprendiz e sua constituição como pessoa. In: GÓES, M. C. R.; LAPLANE, A. L. F. D. Políticas e práticas de Educação Inclusiva.

Campinas: Autores Associados, 2004. p. 49-68.

KASSAR, M. D. C. M. Matrículas de crianças com 
necessidades educacionais especiais na rede de ensino regular: do que e de quem se fala? In: GÓES, M. C. R.; LAPLANE, A. L. F. D. Politicas e Práticas da Educação Inclusiva. Campinas, SP: Autores Associados, 2004. p. 49-69.

NARDES, F.; ARAÚJO, A. P. Q. C.; RIBEIRO, M. G. O retardo mental na distrofia muscular de Duchenne. Jornal de Pediatria, v. 88, n. 1, p. 6-16, 2012.

PINO, A. L. B. Processos de significação e constituição dos sujeitos. Temas em Psicologia. Ribeirão Preto, v. 1, n. 1, pp. 17-24, abr/ 1993.

PINO, A. As Marcas do Humano. Às origens da constituição cultural da criança na perspectiva de Lev S. Vigotski. $1^{a}$ Ed. São Paulo: Cortez Editora, 2005.

POLITZER, G. Crítica dos fundamentos da Psicologia II. $1^{\text {a }}$ Ed. Lisboa: Biblioteca de Ciências Humanas, 1973.

ROCHA, D.; DAHER, M. D. C.; SANT'ANNA, V. L. D. A. A Entrevista em situação de pesquisa acadêmica: reflexões numa perspectiva discursiva. Polifonia, Cuiabá - MT, v. 8, n. 8, p. 1-19, 2004.

SANTOS, A. et al. Caracterização da passagem da postura de bipedestação para a de sedestação no solo em crianças portadoras de distrofia muscular de
Duchene. Revista de Terapia Ocupacional da Universidade de São Paulo. São Paulo, v. 13, n. 1, p. 31-36, jan./abr. 2002.

SMOLKA, A. L. B. Esboço de uma perspectiva teórico metodológica no estudo de processos de construção de conhecimento. In: SMOLKA, A. L. B.; GÓES, M. C. R. A significação nos espaços educacionais: interação e subjetivação. $1^{\mathrm{a} E d}$. Campinas: Papirus, 1997, pp.11-28.

SMOLKA, A. L.B. O (im)proprio e o (im)pertinente na apropriação das práticas sociais. Caderno CEDES. São Paulo: Campinas, v. 1, n.50, p.26-40, 2000.

SOUZA, F. F. Políticas de Educação Inclusiva: análise das condições de desenvolvimento dos alunos com deficiência na instituição escolar. 2013. 277p. Tese (Doutorado em 2013). Campinas: Unicamp, 2013.

VYGOTSKY, L.S. Manuscrito de 1929. Educação \& Sociedade. ano 21, n. 71, p. 21-44, 2000.

VYGOTSKY, L. S. Problemas del Desarrollo de la Psique. In: Obras Escogidas, v.III. $1^{\text {a }}$ Ed. Madrid: Machado, 2012a.

VYGOTSKY, L. S. Fundamentos de Defectologia. In: Obras escogidas, v.V. $1^{\text {a }}$ Ed. Madrid: Machado Libros, $2012 b$.

\section{Sobre as autoras}

Géssica Torres Rozante: Doutoranda do Programa de Pós-graduação em Educação da Universidade Estadual de Campinas (UNICAMP). Especialização em Educação em Saúde: Atendimento Escolar Hospitalar pela Universidade Federal de São Paulo (UNIFESP) Mestre em Educação e Saúde na Infância e Adolescência (UNIFESP). Bacharel e Licenciada em História pela Universidade de São Paulo (USP). Membro do Grupo de Pesquisa Pensamento e Linguagem (GPPL). Atualmente é Orientadora Educacional da Escola Móvel do Instituto de Oncologia Pediátrica (GRAACC/IOP/UNIFESP).

Maria de Fátima Carvalho: Possui Pós-doutorado em Educação (USP). Doutora em Educação pela Universidade Estadual de Campinas (UNICAMP). Mestre em Educação Especial pela Universidade Federal de São Carlos (UFSCAR). Especialista em Educação e Tratamento de Crianças com Transtorno de Desenvolvimento - Instituto de Psicologia (USP). Atualmente é professora do Departamento de Educação da Universidade Federal de São Paulo (UNIFESP) e vinculada ao Programa de Pós-graduação em Educação e Saúde na Infância e Adolescência (UNIFESP).

Recebido em julho de 2018.

Aprovado em outubro de 2018. 